\title{
Delivering quality along with quantity: The challenge of teaching a large and heterogeneous engineering class
}

\begin{abstract}
The challenges faced by a lecturer teaching large multidisciplinary engineering classes are identified. These are principally related to the size of the class, the extensive mathematical knowledge that is considered as prerequisite, as well as the heterogeneity of the class due to the diversity of students' academic background and interests. In order to improve students' engagement and retention in class, active learning techniques are employed and their impact on the performance of the class is captured through a questionnaire designed for this purpose. The statistics demonstrate that good teaching facilities and a well prepared lecturer do not suffice for maximising students' satisfaction, attention and retention. In order to engage the students in a large class setting, it is important to involve them in the lecture process. The employed active learning methods comprising quizzes, in class demonstration and muddiest-point cards induce a remarkably positive impact at almost no additional teaching resources.
\end{abstract}

Keyw ords: Active learning; Mechanical engineering; Large classes; Multidisciplinary classes;

\section{Introduction}

University student numbers in the UK are nowadays at a record high and set to keep increasing at least until 2030 (Boyer 1990; BBC 2013). These record high numbers of students result in unavoidably large classes. The challenges related to teaching such classes have been investigated and discussed by several authors (Deslauriers et al. 2011; Gibbs 1992; Mulryan-Kyne 2010). Among these challenges are the difficulty to control the students behaviour (Carbone 1999), to encourage students participation in class as well as to follow up on students retention. In order to overcome these issues, a variety of teaching approaches under the umbrella term Active Learning have been introduced during the last two decades. Among these approaches the most common include group learning and group work, problem based learning, team-teaching, in-class demonstrations, muddiest card and laboratory work, (Smith et al. 2005; Bonwell and Sutherland 1996; Hall et al. 2002). The focal point of these approaches is giving students the opportunity to escape from their passive role (listening to the lecturer and taking notes) and actively participate in the lecture (Bonwell and Eison 1991). Implementation of active learning approaches requires effort and resources. As stated in (Hall et al. 2002), challenges include the decrease of total covered contents, the increase of preparation effort, and the effort demanded for preparing the relative materials and resources. Active learning can be implemented in both large and small class (following the definition as given in (Kuo 2007)). Active learning has exhibited exceptional results regarding improvement in student's engagement and retention, even if some material has to be dropped from the syllabus due to imposed time constraints (Felder and Brent 1999; Sim and Vogel-Heuser 2010). 
In this paper the author investigates the impact of implementation of teaching improvement strategies on the satisfaction, retention and engagement of first year undergraduate students during the Dynamics of Mechanical Systems (MM1DMS) module at the University of Nottingham. The evaluated teaching improvement strategies include active learning techniques to a large extent. The performed teaching development cycle as proposed in (Kolb and Kolb 2005) is employed in this paper, involving

(1) Undertaking the teaching activity

(2) Reflecting on the feedback and the experience gained by the activity

(3) Interpreting the acquired feedback according to the desired results

(4) Planning and implementing improvement strategies for future teaching

In Sec. 2 the challenges faced by the lecturer during teaching the MM1DMS module are discussed. The results of a questionnaire survey exhibit an obvious dissatisfaction and a low retention by the students when teaching is performed in the traditional passive way. In Sec. 3 the strategies adopted for improving the delivery of the module are presented and selected vis-a-vis the challenges posed by a large and heterogeneous engineering class. In Sec. 4 the impact of the implementation of the new strategy is presented and evaluated. It clearly shows a radical increase concerning student's satisfaction and retention. Conclusions on the presented work are eventually drawn in Sec.5.

\section{Module challenges}

MM1DMS is taught in a modern lecture theatre (see Fig. 1), comprising a complete set of audio-visual facilities. It is an undergraduate module, compulsory for all first year students studying:

(1) Mechanical Engineering

(2) Manufacturing Engineering

(3) Product Design and Manufacture

Figure 1. The Keighton auditorium where MM1DMS lectures take place.

During Year 1 (2014) of teaching MM1DMS, the lecturer identified three major factors that can significantly influence the engagement and retention of students. These were:

(1) The size of the class: The student intake at the department of Mechanical, Materials and Manufacturing Engineering of the university has presented a yearly average increase of approximately 5\% between 2013-'16, with the first year cohort in 2014 comprising 234 students. The large size of the class prohibits personalised interaction with students. Moreover, few students have the confidence to risk looking foolish by asking or answering questions in front of such a large number of classmates which further minimises the interaction during the lectures.

(2) The heterogeneity due to academic background and interest diversity: On top of cultural diversity which is nowadays common to most engineering courses worldwide (Foor et al 2007), the peculiarity of the MM1DMS class is that is also brings together students studying a variety of engineering degrees. More precisely, in 2014 the class consisted of $77 \%$ of students studying Mechanical Engineering, 11\% of students studying Manufacturing 
Engineering and $12 \%$ of students on a Product Design and Manufacture degree. Given that the general 'dynamics' discipline lays at the heart of scientific engineering (see also next factor), it is expected that the students interested in less analytical aspects of engineering will have a tendency to disengage in class.

(3) The amount of prerequisite knowledge required for MM1DMS: As most 'dynamics' modules, MM1DMS requires a large amount of analytical and mathematical skills from students as well as careful and consistent application of these. Inevitably, a large portion of the lectures is dedicated to solving practical examples in class. After lecture, students have the chance to approach the lecturer and pose any questions they may have. It was observed that a small group of students at a weekly basis were posing questions which were mostly related to the mathematical background, considered to be prerequisite for MM1DMS. The heterogeneity of the student's background and skills could thus have a significant impact on their retention in class.

During Year 1, the module was taught using traditional passive learning means, including handouts, PowerPoint slides and exercise sheets solved in class. The exercises were focused on case studies of average difficulty and assumed that students had the prerequisite mathematical knowledge necessary for comprehending the solution procedure. During the case study sessions, it was observed that after the first 15 minutes, most students were neither practicing on the given problem nor asking for feedback on their attempts. They were just sitting there, most probably thinking of other things, sometimes daydreaming.

In order to further understand the impact of the above mentioned factors on the engagement and retention of students in class, a questionnaire was prepared by the lecturer and was distributed to students at the end of Year 1. The questionnaire comprised 10 'attitude questions' related to prerequisite knowledge, engagement, satisfaction, the quality of teaching methods and facilities as well as to the actual level of MM1DMS and can be found in Appendix A of this paper. The results for Year 1 (found in Fig. B1, Appendix B) categorically justified the worries of the lecturer. Approximately $33 \%$ of 159 students that participated to the survey considered that they did not have the prerequisite knowledge for MM1DMS, 59\% found the level of the module not right for them, while only $30 \%$ found the module stimulating. It is interesting to note that $42 \%$ of the students that considered the level of the module inappropriate, actually found it too easy for them; suggesting that while these students had the required skills, they lacked some challenging case studies. Furthermore, more than $75 \%$ of students found the lecturer and the teaching facilities to be satisfactory, while $62 \%$ considered that there was no encouragement for student participation in class. The above observations lead to the conclusion that a two-humped class (Dehnadi and Bornat 2006) is to be taught, with the two humps corresponding to weak and strong students. While the lecturer was aiming for the average student hoping that this category will be the majority in class, it seems that the polarisation of the students' competence level will need a more sophisticated mitigation plan for improving their engagement and retention.

\section{Introducing active learning}

The implementation of active learning in a large class environment can be challenging. In (Arias and Walker 2004) the authors argued that a small class tends to respond better than a larger one. Moreover, the research undertaken to implement active learning in large class environments (Graber and Pionke 2006; Mitsui et al. 2008) showed that oftentimes, a portion of the material has to be dropped from the syllabus while much resources are also required for successful implementation. On the other hand, it has been argued that the larger the class, 
the more difficult ir is to get the students actively involved, therefore the more essential it is to use active learning (Felder and Brent 1999). The approach to follow is periodically giving students an activity to do individually or in groups. A key to making active learning work for large classes is to begin and stop the activity at prescribed timed intervals and call on individuals to check or communicate their results. Three active learning approaches were implemented in MM1DMS during Year 2 (2015) as described below.

\subsection{Problem based learning}

The approach to be adopted is very much related to what is usually referred as Problem Based Learning (PBL). PBL has been extensively covered in literature (De Graaf and Kolmos 2003; Roberts et al. 2005; Pastirik 2006; Pocock 2012) and has been applied to single modules as well as to entire degree courses. In the case of engineering education, PBL is oftentimes used during final year modules (such as design projects) with little scaffolding of learning. The movement towards a PBL teaching in Year 2 included:

(1) The MM1DMS case studies from Year 1 were slightly amended in order to introduce a more engineering background to each one of them. The case studies were now more focused on illustrating the everyday challenges faced by an engineer (working in the field of dynamics) and how the analytical tools studied in class can be used to overcome these.

(2) Additional support for the case studies was made available to students through the online environment of the University (Moodle). The material included audio-visual material illustrating why dynamics are important for engineering safe products.

(3) Case studies with a subject related to the UK transportation industry (mainly aerospace and automotive) were introduced to increase student motivation and engagement.

The greatest difference to Year 1 is that during Year 2 a special 'Problem solving in class' chapter was included in the module handouts. This part of the handouts had specially designed, blank rubrics for students to elaborate on the problem themselves in class. An adequate amount of time was given to students for solving the case study on their own before the solution was worked out by the lecturer. These rubrics therefore provided a mechanism for actively engaging them and verifying their understanding during the lecture.

\subsubsection{Introducing case studies of incremental difficulty}

Teaching a two-hump class (see Section 2) directly implies that in order to retain students attention and interest in the module, the level of the utilised case studies should be adapted to student's capacity. In order to more effectively address the diversified audience, the presented case studies were split into three categories. A third of Year 1 exercises were reduced to an elementary level, another third remained at the same aver- age level, while the remaining were transformed into advanced level case studies which were redesigned to be more challenging but also attracting (by employing realistic engineering case studies) for students. It should be noted that a 'Revision of engineering mathematical tools' was offered at the beginning of all elementary case studies, in order to review the basic mathematical principles (e.g. vector equations, linear algebra e.t.c) for the weaker students.

\subsection{Muddiest-point card}

One of the biggest challenges for teaching large undergraduate classes is identifying the parts of the module that trouble students (especially the weaker ones) the most. A technique that can be used to address this issue is the muddiest point card (Hall et al. 2002). The technique 
is however logistically difficult to implement in such large classes (King 2011). after requesting permission for this, the lecturer was allowed to borrow person- al response devices from the University. These clicker devices can be used to facilitate this technique with students' answer to multiple choice questions appearing live on the screen. An alternative way of performing a similar survey is posing a question with only two possible answers (A and B) and asking the students to present a coloured sheet for answer A, or a white sheet for answer B. In both cases the goal is a fast identification of the 'muddiest point' by the instructor. The use of clickers has the further advantage of allowing students to maintain their anonymity. Incorporation of 7 muddiest-point questions was made throughout the term (4 using clickerdevices and 3 using coloured/blank sheets). To discourage the participation of excellent students in the survey (who would not particularly struggle with any part of the module) an additional option 'I feel comfortable' was added. It was observed that quantitative and mathematics related topics were most likely to be chosen as the muddiest point.

\subsection{Cold Calling - The quiz approach}

A cold calling approach is often effective for instantly capturing students' attendance. To achieve this, the lecturer chose to introduce impromptu quizzes conducted at the midpoint of some of the Year 2 lectures (when students tend to start disengaging). The purpose of pop quizzes is to encourage student's attendance and to give them an exciting tool for verifying how much they have understood in the previous lectures. Ten minutes were given to the students to finish up the quizzes. As marking all quizzes would be prohibitive due to the additional required human resources, the lecturer chose to reward (using small treats) the 10 first students that would write down and bring the correct answer to him. As this approach would not appeal to weak students (who would never be in the first $5 \%$ of the class to solve the problem), the quiz technique was mainly employed for enhancing the engagement of strong students in class.

\section{Impact on student satisfaction, retention and engagement}

While the material covered in the syllabus was reduced by approximately $15 \%$ due to the time constraints imposed by the adopted active learning techniques, Year 2 saw a general increase in student's satisfaction, engagement as well as in their overall average module performance. In order to quantify this increase, the lecturer used the same questionnaire exhibited in Appendix A. The main conclusions out of the 168 questionnaires received by the lecturer are summarized as:

(1) The percentage of students considering that the amount required following MM1DMS is rational increased by $17 \%$, suggesting the introduced elementary exercises as well as the mathematic tool revision had a positive impact.

(2) The percentage of Year 2 students considering that the level of the module is about right for them increased by $21 \%$. It is also important to note that among the disagreeing students, the majority now believes that the module is too easy for them; thus implying that the introduction of active learning techniques has positively influenced weaker students to a higher degree.

(3) An impressive additional $26 \%$ of students found the module stimulating, an extra $25 \%$ considered that they retained useful knowledge out of the module, while $21 \%$ more students compared to Year 1 felt that engagement was encouraged during the lectures, thanks to the implementation of the muddiest-point cards and of the quiz sessions. 
(4) Last but not least, while students' satisfaction with regard to teaching quality and facilities remained at similar to Year 1 levels, an additional $21 \%$ feels that the online provided resources were useful, suggesting that the engineering case studies boosted their engagement and retention outside the class.

Besides the improvement illustrated by the above statistics and the generally positive feedback received by students on the active learning techniques during face-to-face discussions, there was one major issue identified by the lecturer during Year 2. This was that a large portion of students (approximately 30\%-40\%) were uninterested in participating to the active learning activities which consequently increased the noise levels during the activities making it sometimes difficult for the lecturer to regain control of the class. In order to retain control of the class during each activity the lecturer chose to present a chronometer on screen with regular sounds played as time reminders. This proved to encourage a larger portion of students concentrate on the activity, while it makes regaining attention at the end of the activity much easier. With regard to the portion of students focusing on the active learning activities, as argued in (Felder and Brent 1999), this will by no means be inferior to the portion of students focused in a passive lecture session.

\section{Concluding remarks}

In this paper, the challenges faced by a lecturer teaching a large multidisciplinary engineering class were identified and alleviated through the employment of a series of active learning techniques. The satisfaction and retention of students was quantified through a questionnaire designed for this purpose. The results show a 'two-hump' class with the student's being clearly divided into weak and strong with regard to their capacity. Three types of active learning activities, namely problem based learning, quizzes and muddiest-point cards were introduced and assessed through the same questionnaire. In short, it was shown that:

(1) The introduction of a set of elementary case studies can have a positive impact on the confidence and retention of weaker students.

(2) A significant percentage of students felt that the implementation of active learning activities (especially the muddiest-point cards and of the quiz sessions) encouraged students' engagement during the lectures.

(3) Students considered the additional case studies provided online useful, boosting their engagement and retention outside the class.

The statistics exhibit that good teaching facilities and a well prepared lecturer do not suffice for maximising student's satisfaction, attention and retention. In order to engage the students in a large class setting, it is important to involve them in the lecture process. Simple active learning activities may induce a remarkably positive impact at almost no additional teaching resources.

\section{Acknowledgements}

I am grateful to a number of colleagues in the Mechanical Engineering Department of the University of Nottingham (notably Prof. Stewart McWilliam, Prof. Atanas Popov and Dr. Emma Barney) for the fruitful discussions we have had on ameliorating my teaching and lecturing approaches. 


\section{References}

Arias, J., and Walker, D. M. Additional evidence on the relationship between class size and student performance. The Journal of Economic Education 35, 4 (2004), 311-329.

BBC.co.uk, University demand 'to rise by a quarter' says Willetts. http://www.bbc.co.uk/news/education-24579816.

Bonwell, C. C., and Eison, J. A. Active Learning: Creating Excitement in the Classroom. 1991 ASHE-ERIC Higher Education Reports. ERIC, 1991.

Bonwell, C. C., and Sutherland, T. E. The active learning continuum: Choosing activities to engage students in the classroom. New directions for teaching and learning 1996, 67 (1996),3-16.

Boyer, E. L. Scholarship reconsidered: Priorities of the professoriate. The Carnegie foundation for the advancement of teaching 1990.

Carbone, E. Students behaving badly in large classes. New Directions for Teaching and Learning1999, 77 (1999), $35-43$.

De Graaf, E., and Kolmos, A. Characteristics of problem-based learning. International Journal of Engineering Education 19, 5 (2003), 657-662.

Dehnadi, S., and Bornat, R. The camel has two humps (working title). Middlesex University, UK (2006), 1-21.

Deslauriers, L., Schelew, E., and Wieman, C. Improved learning in a large-enrolment physics class. Science 332,6031 (2011), 862-864.

Felder, R. M., and Brent, R. FAQS II. Chem. Engr. Education 33, 4 (1999), 276-277.

Foor, C. E., Walden, S. E., and Trytten, D. A. I wish that I belonged more in this whole engineering group: achieving individual diversity. Journal of Engineering Education 96, 2 (2007), 103-115.

Gibbs, G. Teaching large classes in higher education: How to maintain quality with reduced resources. Psychology Press, 1992.

Graber, G. C., and Pionke, C. D. A team-taught interdisciplinary approach to engineering ethics. Science and engineering ethics 12, 2 (2006), 313-320.

Hall, S. R., Waitz, I., Brodeu, D. R., Soderholm, D. H., and Nasr, R. Adoption of active learning in a lecture-based engineering class. In Frontiers in Education, 2002. FIE 2002. 32nd Annual (2002), vol. 1, IEEE, pp. T2A-9.

King, D. B. Using clickers to identify the muddiest points in large chemistry classes. Journal of chemical education 88, 11 (2011), 1485-1488.

Kolb, A. Y., and Kolb, D. A. Learning styles and learning spaces: Enhancing experiential learning in higher education. Academy of management learning \& education 4, 2 (2005), 193-212.

Kuo, W.-H. Editorial: How reliable is teaching evaluation? The relationship of class size to teaching evaluation scores. Reliability, IEEE Transactions on 56, 2 (2007), 178-181.

Mitsui, H., Kambe, H., Endo, S., and Koizumi, H. A student experiment method for learning the basics of embedded software development including hw/sw co-design. In Advanced Information Networking and Applications-Workshops, 2008. AINAW 2008. 22nd International Conference on (2008), IEEE, pp. 31-37.

Mulryan-Kyne, C. Teaching large classes at college and university level: Challenges and opportunities. Teaching in Higher Education 15, 2 (2010), 175-185.

Pastirik, P. J. Using problem-based learning in a large classroom. Nurse Education in Practice 6, 5 (2006), 261267.

Pocock, J. Project based learning in a large class-a case study in technical communication for engineers. Innovation, Practice, and Research in Engineering Education (2012), 1-12.

Roberts, C., Lawson, M., Newble, D., Self, A., and Chan, P. The introduction of large class problem-based learning into an undergraduate medical curriculum: an evaluation. Medical Teacher 27, 6 (2005), 527-533.

Sim, T. Y., and Vogel-Heuser, B. Reviews and findings on implementing active learning in a large class environment for mechatronics and computer science students. In Education Engineering (EDUCON), 2010 IEEE (2010), IEEE, pp. 1563-1572.

Smith, K. A., Sheppard, S. D., Johnson, D. W., and Johnson, R. T. Pedagogies of engagement: Classroombased practices. Journal of engineering education 94, 1 (2005), 87-101. 


\section{Appendix A: The employed questionnaire}

The questionnaire designed for acquiring information on student satisfaction, retention and engagement can be seen in Fig. A1. The same questionnaire was employed for both Years 1 and 2 .

Figure A1. The questionnaire used to obtain students' feedback on the MM1DMS module.

\section{Appendix B: Results on the survey}

The results obtained through the questionnaire are presented in Figs. B1, B2.

Figure B1. The results obtained for the 10 attitude questions for Year 1 (left) and Year 2 (right), with: DA-Definitely Agree, A-Agree, NAD-Neither Agree or Disagree, D-Disagree and DDDefinitely Disagree.

Figure B2. Results obtained on the Y/N question related to the level of MM1DMS class for Year 1 (left) and Year 2 (right). 